Article

\title{
Properties of Particleboard Made from Recycled Polystyrene and Cocos Nucifera Stem Particles
}

Adeniran A. T.

How to cite this paper: Adeniran, A. T. (2021). Properties of Particleboard Made from Recycled Polystyrene and Cocos Nucifera Stem Particles. Open Journal of Agricultural Research, 1(1), 1-7. DOI: 10.31586/ojar.2021.010101. Retrieved from https://www.scipublications.com/journal/index.php/ojar/article/view/11

Received: April 19, 2021

Accepted: June 12, 2021

Published: June 13, 2021

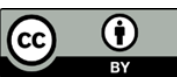

Copyright: (c) 2021 by the authors. Submitted for possible open access publication under the terms and conditions of the Creative Commons Attribution (CC BY) license (http://creativecommons.org/licenses /by/4.0/).
Department of Forestry and Wood Technology, Federal University of Technology Akure, Ondo State, Nigeria.

* Correspondence: adeniranabiolateslim@gmail.com

\begin{abstract}
The study investigates the use of Recycled Polystyrene (RP) in the production of particleboard. Boards of $6 \mathrm{~mm}$ thickness with dimension of $350 \mathrm{~mm}$ x $350 \mathrm{~mm}$ were produced from mixture of Cocos nucifera stem particles and RP. The boards were made at varying mixing ratio of 1:1, 2:1, and 3:1 and board densities of $1000 \mathrm{~kg} / \mathrm{m} 31100 \mathrm{~kg} / \mathrm{m} 3$ and $1200 \mathrm{~kg} / \mathrm{m} 3$. Thickness swelling (TS), Water Absorption (WA), Modulus of Rupture, and Modulus of Elasticity of the boards were evaluated in accordance to ASTM D-1037 standard. Data obtained were subjected to analysis of variance (ANOVA) at 5\% probability level. TS and WA decreases as the mixing ratio increases from 1:1 to 3:1 and board density increases from $1000 \mathrm{~kg} / \mathrm{m} 3$ to $1200 \mathrm{~kg} / \mathrm{m} 3$. Also, MOR and MOE of boards increase as the board density was increased from $1000 \mathrm{~kg} / \mathrm{m} 3$ to $1200 \mathrm{~kg} / \mathrm{m} 3$. However, MOR and MOE of boards initially increase as mixing ratio increases from 1:1 to 2:1 and later decreases with further increase in mixing ratio. The strongest and most dimensionally stable board was produced at board $1200 \mathrm{~kg} / \mathrm{m} 3$ and mixing ratio 2:1. This study proves that RP is a good substitute for formaldehyde based resin commonly used in particle boards industries.
\end{abstract}

Keywords: Recycled polystyrene, Particleboard, Coconut stem particles

\section{Introduction}

Particleboard is a wood based composite panel which comprises of lignocellulosic materials combined together with a binder usually under heat and pressure. In the past recent decades, the production of this wood based composites panels has provided a major alternative to solid wood [1-3]. The demand for composite wood products of various genres has increased significantly throughout the world [4], particularly, in applications including housing infrastructure delivery, interior decoration, manufacturing of furniture, flooring, and work surfaces in offices, educational establishments, laboratories and other domestic and industrial needs [5]. Consequently, this enormous demand for particleboard has put the scanty natural forest resources on accelerating pace of disappearance which is raising an alarm on the continuous supply of raw material to the wood based sectors in the future [6]. Hence, the explorations of alternative sources of raw materials for particleboard production technology become crucial. The use of agricultural residues and non-wooden plant fibres as alternatives to wood materials in manufacturing of wood based panels plays a major role in reducing the demand for solid wood and mitigation of environmental pollution [7].

Coconut (Cocos nucifera) is a good alternative to wood material and belongs to group angiosperms and order monocotyledon. Cocos nucifera has served as alternative to wood lumber in various applications and is a probable raw material for wood based panel production [8]. In Nigeria there are many coconut trees both in plantations and homestead which after they have gone senile are cut down and burned down or allowed to decay; this practice does not utilize the valuable lignocellulosic stem which could serve as raw material for composite panel products. The utilization of Coconut stem particles 
for the production of composite panel products will results in numerous benefits, such as the economic advantage of manufacturing low cost panel products, reduce pressure on frequently used tropical wood species.

Conventionally, particleboards are produced from chosen particles adhered together with a formaldehyde based resin synthesized from petrochemical raw materials [9]. These formaldehyde based resin are expensive and usually imported [10]. Added problem with the use of such resins is the emission of formaldehyde. Exposure to formaldehyde in concentrations greater than 0.1 parts per million (ppm) has been reported to cause nasal and throat congestions, burning eyes, or headaches as well as increased risk of developing cancer [10]. The Idea of replacing the fast depleting petrochemical raw material with other environmentally friendly choice is always desired. This research is therefore designed to substitute formaldehyde based resins that are known to emit carcinogenic gases with a synthetic resin produced from polystyrene wastes.

The objective of this study is to investigate the suitability of producing particleboard at room temperature from spent Coconut (Cocos nucifera) stem particles and polystyrene wastes dissolved in premium motor spirit and also to assess the properties of the panels.

\section{Materials and Method}

The polystyrene (a hard, solid and versatile plastic material) waste used in this study was collected from Centre for Renewable Energy Technology (CRET) construction site, located behind School of Engineering and Engineering Technology, Federal University of Technology Akure, Akure, Ondo State. The polystyrene wastes were cleaned to remove debris and then shredded into small and uniform sizes.

Senile coconut stem used for this study was collected at the stump site using power saw and cross-cut into disc, sliced into flakes using a chipping machine, and reduced into heterogeneous particles using a hammermill. The particles were soaked in a mixture of detergent and ash for (7) seven days to remove the superfluous materials capable of interfering with the internal bond structure. Thereafter, the material was washed thoroughly with cold water and spread out in open air to attain moisture content of about $12 \%$. Subsequently, the particles were fractionalized into the two particle sizes using sieves of mesh sizes $0.5 \mathrm{~mm}$ and $1.0 \mathrm{~mm}$ for the manufacturing of fine and coarse composite boards respectively.

Required quantities of Senile coconut stem particles and Polystyrene were measured at different mixing ratio of wood/resin ratio level of MR1 (1:1), MR2 (1:2) and MR3 (1:3) and board density of BD1 $(1000 \mathrm{~kg} / \mathrm{m} 3)$, BD2 $(1200 \mathrm{~kg} / \mathrm{m} 3)$ and BD3 $(1200 \mathrm{~kg} / \mathrm{m} 3)$. Prior to board manufacturing, $59 \mathrm{~g}$ by mass of polystyrene waste was dissolved in $100 \mathrm{ml}$ of premium motor spirit to obtain synthetic Polystyrene Based Resin (PBR). The PBR obtained was mixed with the senile coconut stem particles. Thereafter, the mixture was formed inside a mould of dimension $350 \mathrm{~mm} \times 350 \mathrm{~mm}$ on a caul plate treated with spent oil to ease de-molding. The mattress formed was placed under hydraulic press for 24 hours. Thereafter panels were de-moulded and stored in the laboratory environment for 28 days for post-curing. Subsequently, panels were trimmed and cut into various sizes prior to test.

Specimen size of $50 \mathrm{~mm} \times 50 \mathrm{~mm}$ in each produced board was measured and subjected into water immersion treatment in cold water for 24 and 48 hours respectively. This test was carried out to examine the behavior of the boards to water exposure. Thickness Swelling and Water absorption is expressed as the percentage of increase in thickness of the board over the initial thickness and increase in weight per unit weight of the board respectively.

Specimens of dimensions $194 \mathrm{~mm}$ x $50 \mathrm{~mm}$ were used to investigate Modulus of Elasticity (MOE) and Modulus of Rupture (MOR). The Modulus of Rupture is the maximum carrying capacity of a wooden member, while Modulus of Elasticity is the measure of the stiffness properties of the board which was determined by conducting a bending test on 
the board. Both properties were determined using a Universal testing in accordance with the America Standard Testing Machine (ASTM).

\section{Experimental design}

The statistical model used for this study was $2 \times 3 \times 3$ factorial experiment in completely randomized design (CRD), with 2 levels of particle size (fine and coarse), PBR/Senile coconut stem particles mixing ratios $(1: 1,1: 2$ and 1:3) and board density $(1000 \mathrm{~kg} / \mathrm{m} 3$, $1100 \mathrm{~kg} / \mathrm{m} 3$ and $1200 \mathrm{~kg} / \mathrm{m} 3$ ) translating into six (18) experimental boards.

The $2 \times 3 \times 3$ factorial experiment in completely randomized design (CRD) was analyzed using Statistical Package for Social Science (SPSS) to investigate the influence of particle size, mixing ratios and board density on the physical and mechanical properties of the composites. In line with assumptions of Analysis of Variance (ANOVA) the data set obtained from the water absorption and thickness swelling as expressed in percentage were transformed using square root transformation prior to analysis.

\section{Results and Discussions} Board

Effects of Density and Mixing Ratio on the Dimensional Stability of the Composite

The mean values of thickness swelling and water absorption after 24-hours and 48hour water immersion were presented in Figure 1 and Figure 2. The mean values obtained for thickness swelling after 24 hours water immersion ranged from $0.83 \pm 0.01 \%$ to $2.74 \pm 0.02 \%$ for boards made from fine particles and $0.62 \pm 0.01 \%$ to $2.44 \pm 0.01 \%$ for boards made from coarse particles, while the mean values obtained for thickness swelling boards made from fine particles and coarse particles after 48 hours water immersion ranged from $0.91 \pm 0.01 \%$ to $5.18 \pm 0.01 \%$ and $0.64 \pm 0.01 \%$ respectively.

The result shows significant $(\mathrm{p} \geq 0.05)$ decrease in thickness swelling and water $a b-$ sorption with increasing board density and mixing ratio. The decrease in TS and WA with increasing density indicates that water could not easily penetrate the high density faces of boards. Board density reflects the quantity of materials per unit area in the board produced and increase in this quantity of material per unit area aided effective compaction of the board because there is more fibre-to-fibre bond [11]. The high density faces of board were as a result of adequate compression and better inter-particle contact. This suggest that greater compaction of the boards was achieved due to an increase in the number of bonds caused by interfacial contact areas between the particles, elimination of void spaces, and the dense surface of the boards [1]. This observation corroborates with the finding of Falemara et. al. [12]. Ajayi et al. [13] also made similar observation while he was investigating the dimensional stability of wood plastic composite produced from Ceiba pentandra sawdust.

The decrease in thickness swelling and water absorption with increasing mixing ratio in this study is as a result of more senile coconut stem particles being adequately coated by the PBR resulting in sufficient encasement of particles by the binder and much less absorption capacity when immersed in water [14]. The impact of mixing ratio on thickness swelling and water absorption can be explained by the differences in absorptive capacity of coconut stem particles and plastics [15]. Coconut stem particle like other lignocellulosic materials are hygroscopic in nature due to the presence of hydroxyl and other polar groups, while polystyrene on the other hand is hydrophobic in nature and could not hold or retain water. This claim conforms to the discoveries of Ajayi [1] that mixing ratio influences the absorptive capacity of boards thereby affecting the thickness swelling and water absorption. This agrees with the report by Aina and Ajayi [16] and Aina et. al. [17] that board properties such as weather resistance, thickness swelling and water absorption can be modified positively by proper adjustment of plastic content. Result also revealed 
that the longer the boards stayed in water the greater the amount of water they absorb, thereby increasing the weights and thicknesses.

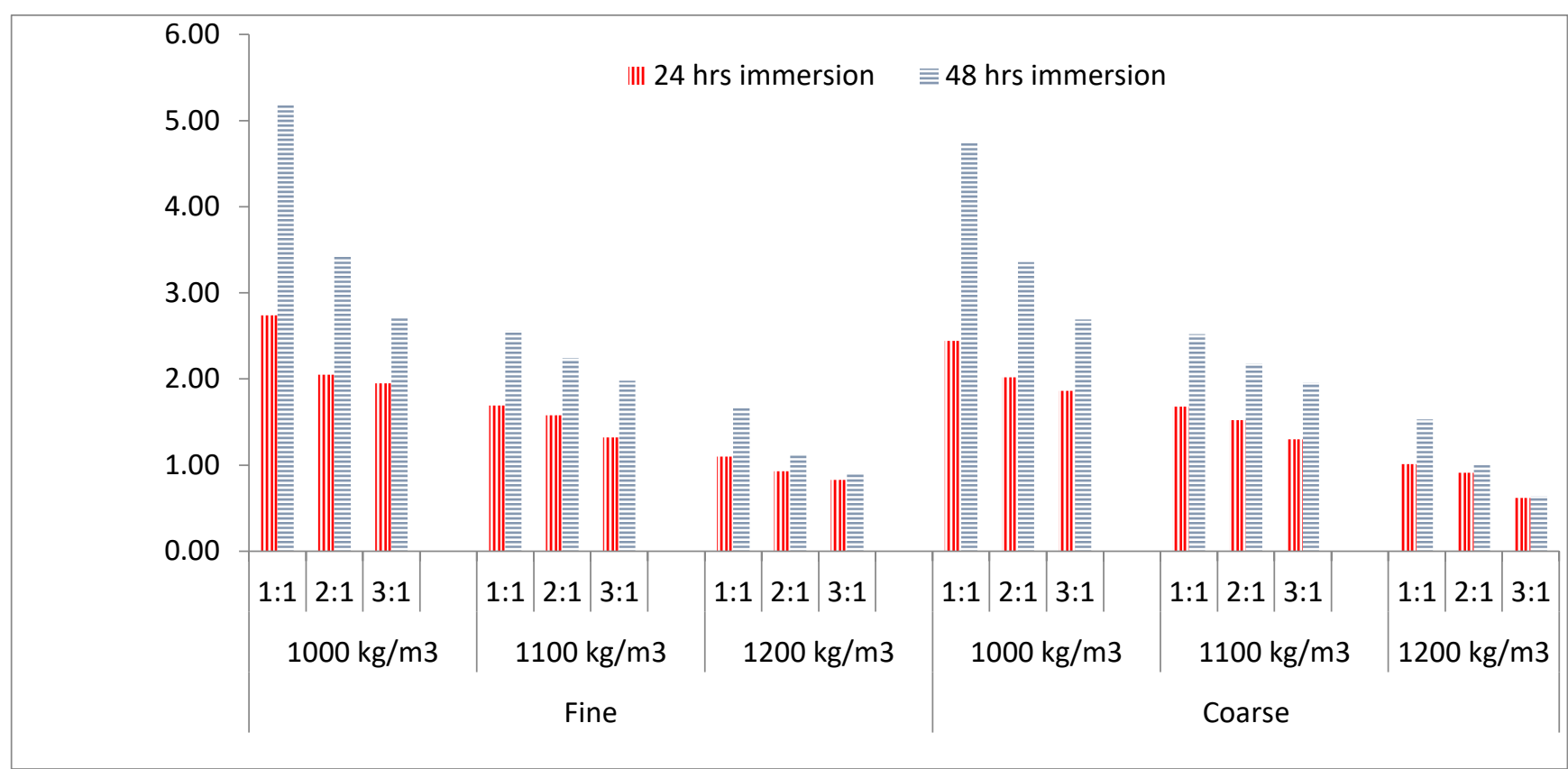

Figure 1. Effect of Particle size, Density and Mixing Ratio on Thickness Swelling (\%) of the PBR Bonded Board after 24hrs and 48hours immersion in water

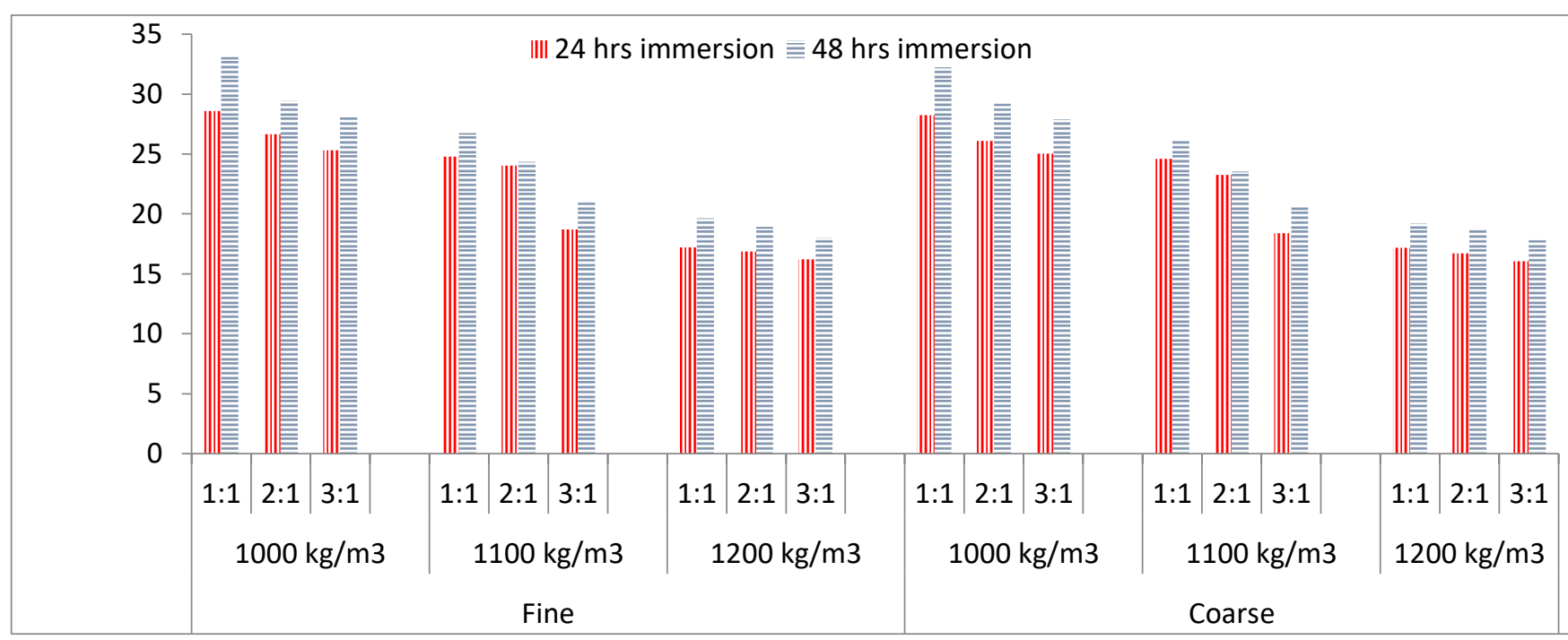

Figure 2. Effect of Particle size, Density and Mixing Ratio on Water Absorption (\%) of the PBR Bonded Board after $24 \mathrm{hrs}$ and 48 hours immersion in water

\subsection{Effects of Particle Size, Board Density and Mixing Ratio on the Strength Properties of the Composite Board}

The mean values obtained for modulus of rupture for fine particle and coarse particle boards ranged from $172.21 \pm 4.68 \mathrm{~N} / \mathrm{mm}^{2}$ to $906.56 \pm 21.91 \mathrm{~N} / \mathrm{mm}^{2}$ and $180.19 \pm 2.34 \mathrm{~N} / \mathrm{mm}^{2}$ to $1105.91 \pm 37.26 \mathrm{~N} / \mathrm{mm}^{2}$, respectively (Figure 3). The mean values obtained for modulus of elasticity for fine particle and coarse particle boards ranged from $24.75 \pm 0.00 \mathrm{~N} / \mathrm{mm}^{2}$ to 
$165.38 \pm 5.83 \mathrm{~N} / \mathrm{mm}^{2}$ and $30.00 \pm 2.12 \mathrm{~N} / \mathrm{mm}^{2}$ to $187.50 \pm 20.15 \mathrm{~N} / \mathrm{mm}^{2}$, respectively (Figure 3). These values compared favourably with values obtained in previous studies involving the development of particle boards from plastic wastes [18-21]. The result revealed that as board density increases, modulus of rupture and modulus of elasticity increases significantly ( $\mathrm{p} \geq 0.05)$. This therefore implies that the higher the board density, the higher the resistance to bending strength and stress elongation stiffness of the board. This observation is in agreement with past findings of Ajayi et. al. [14]; Aina et. al. [19]; and Adhikary, [23] that increase in board density increases the mechanical properties (MOE and MOR) of plastic bonded composite. The increase in modulus of rupture and modulus of elasticity with increasing board density indicates that the highly compressed boards are able to show better resistance to bending forces. The improved resistance of high density boards is as a result of adequate compression, better inter-particle contact and increased number of bonds between adjacent particles. This results in high resistive strength to external bending and elongation forces. The weaker strength and stiffness property of boards produced at lower density of $1000 \mathrm{~kg} / \mathrm{m}^{3}$ is due to the lower quantity of material per unit area which may have resulted in inadequate compression of the board matrix and subsequent fissure at the interface of composite. These may have led to the inability of the matrix to support stresses. In general, board density is observed to have influenced the compression pattern of the boards thereby affecting the modulus of rupture and modulus of elasticity.

The result also showed that the modulus of rupture and modulus of elasticity of board also increased significantly $(p \geq 0.05)$ with increase in PBR-senile coconut stem particles mixing ratio, but a limit of proportionality was reached at PBR-senile coconut stem particles mixing ratio of 2:1, after which additional increase in plastic-senile coconut stem particles mixing ratio results in decreased board strength and stiffness. The initial increase in the strength properties of board implies that as PBR content increases before it reaches its limit of proportionality, stronger board is produced. This finding confirms the reports of previous studies $[1,3,12,13,14,16]$ that bending strength of particle board is enhanced by increase in plastic content because particles of such boards are adequately encased in the plastic and thereby provide better enhancement of the inter-particles contact during formation.

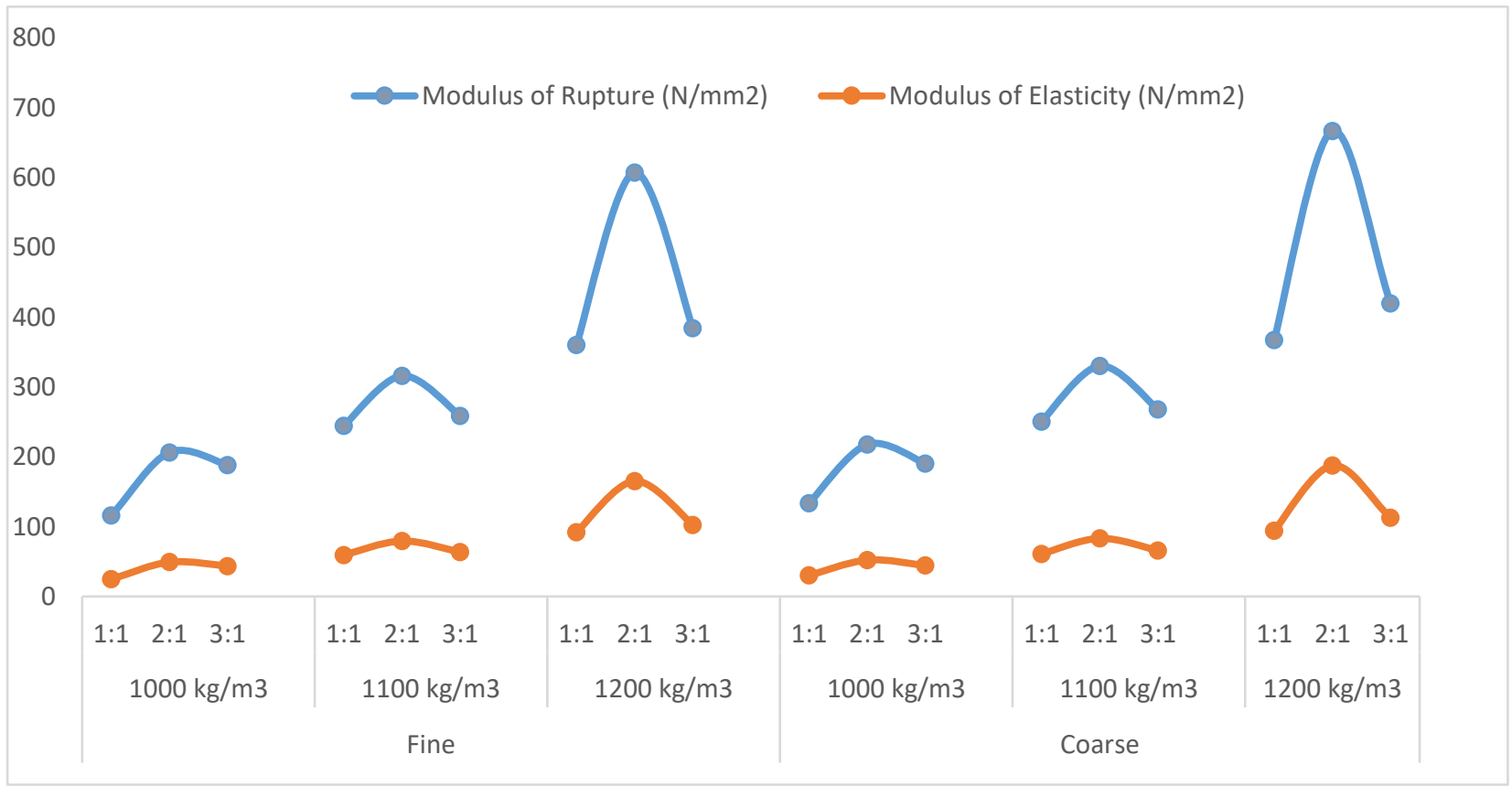

Figure 3. Effects of Particle Size, Board Density and Mixing Ratio on Strength Properties (MOR and $\mathrm{MOE}$ ) of the Composite Board 
It was also obtained that boards made from coarse particles have significantly $(p \geq 0.05)$ higher Modulus of rupture and modulus of elasticity values than boards made from fine particles. This may be because fine particles easily agglomerate and agglomeration limits inter-matrix load transfer thereby causing cracks to initiate and propagate easily. The cracks produced reduced the strength and stiffness of the composite. This decrease in strength and stiffness properties could therefore be attributed to the crack formation at the interface of composite, inability of the agglomerated fine particles to support stresses and poor interfacial bonding between particle and matrix materials which generates a weak structure. Chen et al. (2006) reported similar results regarding the effects of particle size on mechanical properties of Plastic Bonded Composites from polyethylene and wood particles.

\section{Conclusions}

The result of this study has shown that senile coconut stem particle and polystyrene wastes are suitable for the production of value added particleboards. The dimensional stability (TS and WA) of the board is enhanced at increased level of mixing ratio and board density. MOR and MOE of boards are also enhanced with increase in density. However, increase in the proportion of PBR in the mixture initially increases the mechanical properties (MOE and MOR) of boards up to the limit of proportionality (2:1), the point beyond which further increase in PBR proportion reduces the strength of boards. Highly dimensionally stable, strong and stiffened board was produced at the highest level of particle size (fine), board density $(1200 \mathrm{~kg} / \mathrm{m} 3)$ and mixing ratio $(2: 1)$. Coarse particles based boards are found to be more dimensionally stable and possess better strength and stiffness properties than boards with fine particles.

\section{Declaration of Conflict of Interests}

The author declares that there is no conflict of interest. They have no known competing financial interests or personal relationships that could have appeared to influence the work reported in this paper.

\section{References}

[1] Ajayi, B. (2006). Properties of maize stalk based cement bonded composites. Forest Product Journal, 56 (6): 51-55.

[2] Mohanty B. N., Sujatha. D. U. and Day. D. N. (2015). Bamboo Composite material: Game - changer for developing economies; Proceedings of the 10th World Bamboo Congress, Korea.

[3] Ajayi B., Adeniran A. T., Falade O. E., and Alade B. O. (2019). Characterization of Plastic Bonded Composites Reinforced with Delonix Regia Pods. SWST 2019 International Convention. Tenaya Lodge, Yosemite National Park, California, USA.

[4] Chen, H. C., Chen, T. Y., Hsu, C. H. (2006). Effects of wood particle size and mixing ratios of HDPE on the properties of the composites. Holz Roh Werkst 64(3):172-177

[5] Laemlaksakul V., and Kaewkuekool S., "Laminated bamboo materials for furniture - A systematic approach to innovative product design," WSEAS Trans. on Advances in Eng. Education, 5(3): 424-430 2006.

[6] Sellers T., “Growing markets for engineered products spurs research,” Wood Technol.,127(3):40-43, 2000.

[7] Boonstra M. J., Pizzi A., Ohlmeyer M. and Paul W. (2006). The effects of a two stage heat treatment process on the properties of particleboard, European Journal of Wood and Wood Products. 64:157-164.

[8] Subramanian, S. K. V. (2003). “Senile coconut stem diversification for increased income," Indian Coconut Journal. August Edition, 9-18.

[9] Yang T. H., Lin C. J., Wang S. Y., and Tsai M. J., "Characteristics of particleboard made from recycled wood-waste chips impregnated with phenol formaldehyde resin," Building and Environment.:42(1):189-195. 2007.

[10] Idris U. D., Aigbodion V. S., Gadzama R. M. and Ahmed T. Y. (2012) Suitability of maize cob particles and recycled low density polyethylene for particleboard manufacturing. Materials Science, MSAIJ 8(1):34-37.

[11] Olufemi, A.S., Abiodun, O. O., Omaojor O. and Paul, F. A. (2012). Evaluation of Cement Bonded Particle boards made from Banana stalk (Musa sapientum). Global Journal of Advance Engineering Technologies and Sciences. 2(675):2349-2368.

[12] Falemara B. C., Ajayi, B., Badejo S.O. and Adelusi E.A. (2015). Strength and Sorption Properties of Bamboo (Bambusa Vulgaris) Wood-Plastic Composites. Proceedings of the Forest and Forest Products Conference in Atlanta Georgia USA June 2015. 
[13] Ajayi, B. (2010). The Use of Coconut Fibre, a non-convetional material for Inorganic bonded Manufacturing: Mitigating approach to scares housing products. 1 Pro-African Conference: Non- Conventional Building Materials Based on Agroindustrial Wastes. Pirassununga/SP- Brazil. 166-169.

[14] Ajayi, B., Ajigbon, A. A., Oyerinde, V. O., Awopetu, O. O., Taiwo A. A. and Adamolekun O. R. (2012). Adaptive characteristics of plastic bounded made from processed bean pods (Vigna unguicuata) flakes. Proceedings of the 66th International Convention of the Forest Products Society. 3-5 June 2011.

[15] Carus M., Eder A., Dammer L, Korte H., Scholz L., Essel R., Breitmayer E., Barth M., (2015) Wood-plastic composites (WPC) and natural fibre composites (NFC): Global markets and future trends in automotive and Construction Sector. Journal of Bio-Resources, 5(3): 1336-1352.

[16] Aina, K. S., Osuntuyi, E. O. and Aruwajoye A. S. (2013). Comparative Studies of Physico-mechanical properties of Wood Plastic Composites produced from three indigenous wood species. International Journal of Science and Research. $2(8): 178$.

[17] Ajayi, B and Aina K. (2010). Production of Plastic bonded panels from waste materials. XXIII International Union of Forest Research Organization (IUFRO) World Congress, 23-28 August, 2010.Seoul, Korea. Abstract. The International Forestry Review 12(5):278. [Korea, 70\% Contribution].

[18] Stark N. M., Ibach, R. E., and C. Clemons. (2003). Combined ultraviolet and water exposure as a preconditioning method in laboratory fungal durability testing. In: Seventh International Conference on Woodfiber- Plastic Composites, N. Stark (Ed.), May 19-20, 2003, Madison, Wisconsin; Forest Products Society, Madison, Wisconsin. 61-67.

[19] Aina, K. S., Badejo, S. O., Baiyewu, R. A., Ademola, I. T., Taleat, O. S., Agbigbi, J. O. and Alao, O. J. (2008). Assessment of Dimensional Stability of Plastic bonded particleboard produced from Gmelina arborea. African Journal of Agricultural Research and Development, 1 (1), pp. $98-103$.

[20] Zheng, Y.; L. P. Zhongli, R. H. Zhang, B. M. Jenkins and S. Blunk. (2007). Particleboard Quality Characteristics of Saline Jose Tall Wheatgrass and Chemical Treatment Effect. Bioresource Tech. 98(6), pp. 1304-1310.

[21] Ajayi B., Ajigbon A. A. and Adeyemi O. A. (2011). The effect of board density and mixing ratio on mechanical properties of plastics bonded board produced from "Afara" (Terminalia superba) sawdust. Book of Biographies and Abstracts of the 65th International Convention of the Forest Products Society. Portland, Oregon USA. 105.

[22] Adhikary, K. B., Pang, S. and Staiger, M. P. (2008). Dimensional stability and mechanical behaviour of wood-plastic composites based on recycled and virgin high-density polyethylene (HDPE). Compos B Eng 39(5):807-815 